\title{
The Microstructure Evolution of Thermal Deformation of Continuous Extrusion Copper Bus Bar
}

\author{
Jing Lư ${ }^{1}$, Gaosheng Fu², Zhimeng Ren ${ }^{1}$, Jie Liu ${ }^{1}$ and Huan Hao ${ }^{1}$ \\ ${ }^{1}$ Xi'an Hitech Institute, Shaanxi, China \\ ${ }^{2}$ Fuzhou University, Fujian, China
}

\begin{abstract}
The thermal deformation microstructure of continuous extrusion copper bus bar was observed and analyzed in the temperature range from $200^{\circ} \mathrm{C}$ to $700^{\circ} \mathrm{C}$ and at strain rate from $0.01 \mathrm{~s}^{-1}$ to $10.0 \mathrm{~s}^{-1}$ and at deformation amount from $30 \%$ to $90 \%$ on Gleeble 1500 test machine. The experiment results show that the higher the temperature, the lower the strain rate, the more dynamic recrystallization occurred. At the same strain rate, the copper bus bar changes from raw material of as-cast organization to recrystallization grain gradually as the deformation temperature and deformation degree increase, and the recrystallization grain size grows older with the rise of temperature. At the same deformation temperature, the temperature of recrystallization nucleation decreases while the strain rate increases. At low strain rate $\left(0.01 \sim 1.0 \mathrm{~s}^{-1}\right)$, the dynamic recrystallization occurred at $500^{\circ} \mathrm{C}$. While at high strain rate $\left(10.0 \mathrm{~s}^{-1}\right)$, the recrystallization nucleation is advanced and it is already completed at $500^{\circ} \mathrm{C}$. The $Z$ parameters can be used to express the effect of deformation temperature and strain rate on the average grain size $\mathrm{D}$, and the prediction model of the thermal deformation microstructure is obtained as follows: $\ln D=4.822-0.018 \ln Z$.
\end{abstract}

Because of good corrosion resistance and large carrying capacity, copper bus bar are often used in power transmission or transformation equipments in hydropower plants, nuclear power plants, subways, airports, high-speed trains and so on. In China, ways to produce the copper bus bar mainly are rolling, extrusion and CONFORM-continuous extrusion. Owing to simpler process line and adaption to all produce specifications, the continuous extrusion has developed quickly and has been widely used these years. Moreover, it improves the performance of the copper bus in both strength and conductivity. Consequently, the yield rises with lower energy cost ${ }^{[1-3]}$. As previous studies on the emerging production technology mainly focus on equipment, technology and numerical simulation ${ }^{[4-8]}$, the high temperature plastic deformation behavior of the material is proposed ${ }^{[9-11]}$ and studied in this paper to improve the technology.

\section{Experimental method}

The updraft continuous casting pure copper rod, the raw material for copper bus bas production, is compressed at rising temperature and constant temperature respectively by Gleeble 1500 thermal simulation test machine ${ }^{[12]}$. The specimen size of the cylinder is $10 \mathrm{~mm} \times 15 \mathrm{~mm}$. Considering characteristics of continuous extrusion process ${ }^{[1-3,13]}$, copper rods are divided into two groups for their deformation microstructure. For one group, the deformation is set to $50 \%$, while the deformation temperature varies from $200^{\circ} \mathrm{C}$ to $700^{\circ} \mathrm{C}$ and the strain rate varies from $0.01 \mathrm{~s}^{-1}$ to $10.0^{-1}$. For the other group, the deformation temperature stays at $600^{\circ} \mathrm{C}$ and the strain rate is, the final deformation amount are $30 \%, 70 \%$ and $90 \%$. For all experimental objectives, the heating rate is $200^{\circ} \mathrm{C}$ per minute and the holding time is 3 minutes. Samples are quenched into the water immediately after being compressed at high temperature to make the deformed microstructure fixed and unchangeable. To prepare the metallographic samples, thermal deformed specimens are cut along the longitudinal section, paralleling to the compression direction by the wire cutting machine firstly. And then mechanical polishing and electro polishing are taken respectively by the PG-Z metallographic sample polisher and YJ63 DC stabilized current. The thermal deformations of microstructures are observed and photographed in polarized state by large XJG-05 metallographic microscope xenon lamp. Grains of different parts are measured by TCI image analysis system. Accordingly, the average grain size is calculated by the wire cutting method. To make the measurement more accurate, view fields and grains intercepted by each line should be as much as possible. Therefore, 20 fields are observed to calculate the average grain size.

\section{Experimental results and analysis}

\subsection{Characteristics of thermal deformation microstructure of copper bus bar}


Figure 1 to 4 is the grain morphologies of the thermal deformed copper bus bar samples. The deformation temperature ranges from $200^{\circ} \mathrm{C}$ to $700^{\circ} \mathrm{C}$ and the strain rate varies from $0.01 \mathrm{~s}^{-1}$ to $10.0 \mathrm{~s}^{-1}$. The thermal deformation rate is $50 \%$.

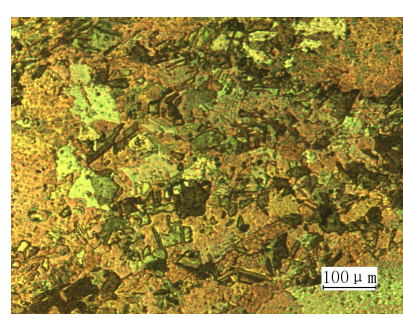

(a) $\mathrm{T}=300^{\circ} \mathrm{C}$

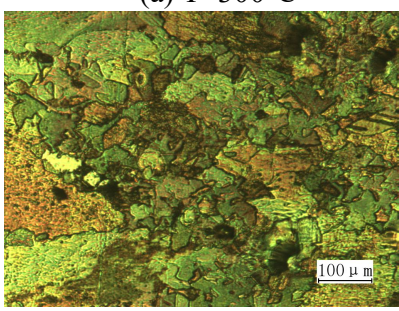

(c) $\mathrm{T}=500^{\circ} \mathrm{C}$

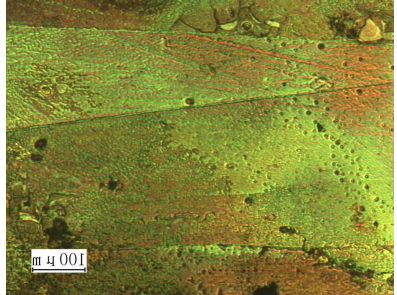

(b) $\mathrm{T}=400^{\circ} \mathrm{C}$

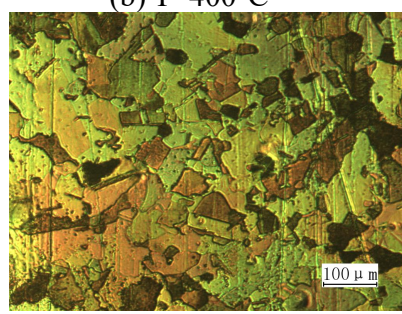

(d) $\mathrm{T}=600^{\circ} \mathrm{C}$

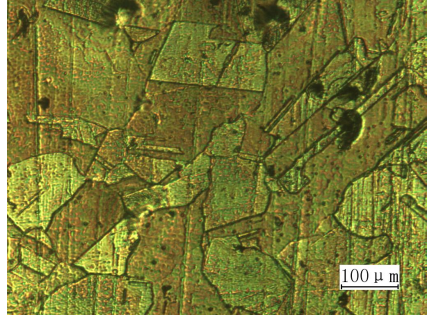

(e) $\mathrm{T}=700^{\circ} \mathrm{C}$

Figure 1. Thermal deformation organization of copper bus bar $\left(\mathrm{e}=50 \%, \dot{\varepsilon}=0.01 \mathrm{~s}^{-1}\right)$.

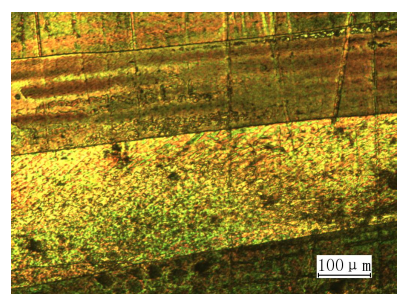

(a) $\mathrm{T}=200^{\circ} \mathrm{C}$

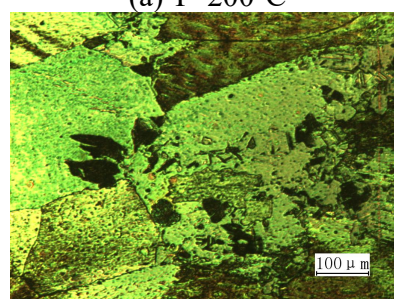

(c) $\mathrm{T}=400^{\circ} \mathrm{C}$

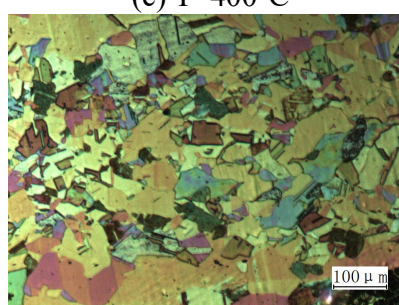

(e) $\mathrm{T}=600^{\circ} \mathrm{C}$

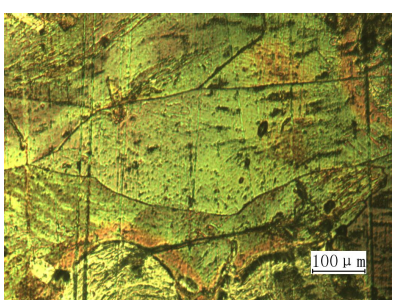

(b) $\mathrm{T}=300^{\circ} \mathrm{C}$

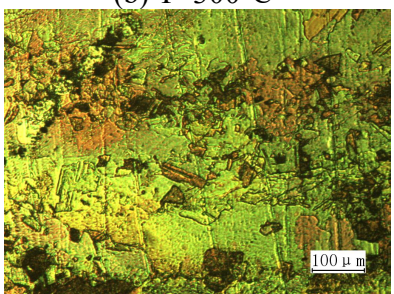

(d) $\mathrm{T}=500^{\circ} \mathrm{C}$

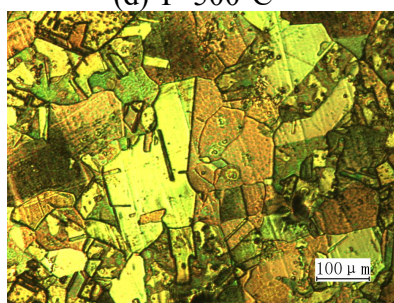

(f) $\mathrm{T}=700^{\circ} \mathrm{C}$
Figure 2. Thermal deformation organization of copper bus bar $\left(\mathrm{e}=50 \%, \quad \dot{\varepsilon}=0.1 \mathrm{~s}^{-1}\right)$.

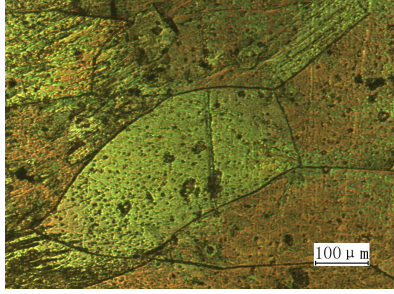

(a) $\mathrm{T}=300^{\circ} \mathrm{C}$

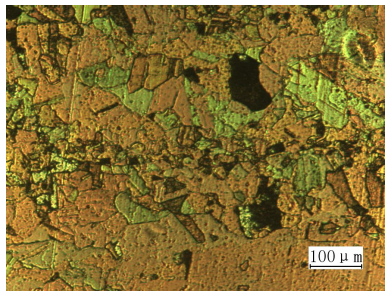

(c) $\mathrm{T}=500^{\circ} \mathrm{C}$

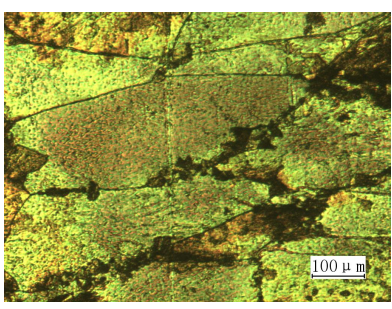

(b) $\mathrm{T}=400^{\circ} \mathrm{C}$

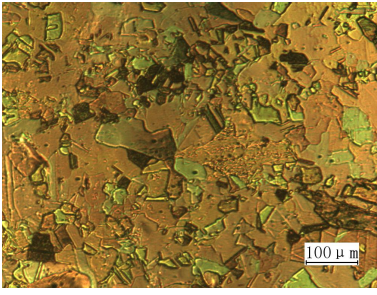

(d) $\mathrm{T}=600^{\circ} \mathrm{C}$

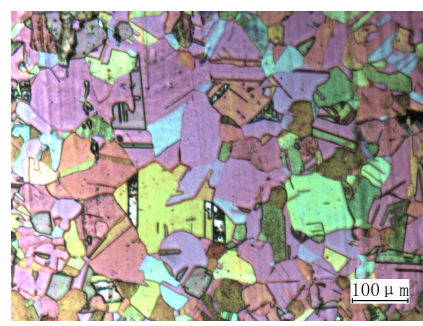

(e) $\mathrm{T}=700^{\circ} \mathrm{C}$

Figure 3. Thermal deformation organization of copper bus bar $\left(\mathrm{e}=50 \%, \dot{\varepsilon}=1.0 \mathrm{~s}^{-1}\right)$

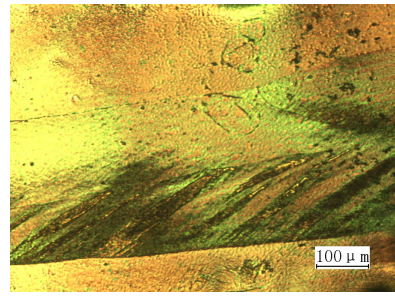

(a) $\mathrm{T}=300^{\circ} \mathrm{C}$

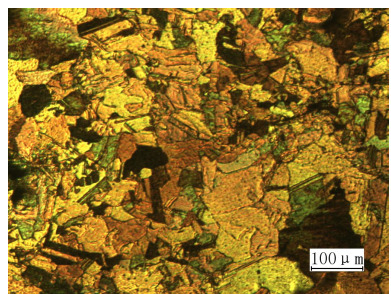

(c) $\mathrm{T}=500^{\circ} \mathrm{C}$

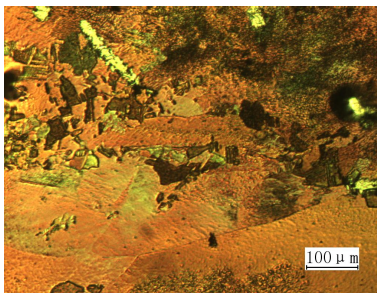

(b) $\mathrm{T}=400^{\circ} \mathrm{C}$

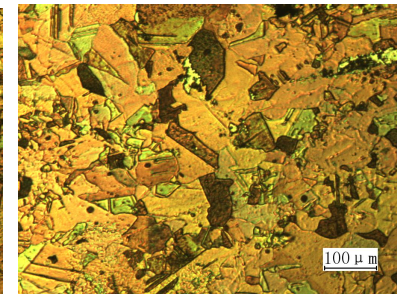

(d) $\mathrm{T}=600^{\circ} \mathrm{C}$

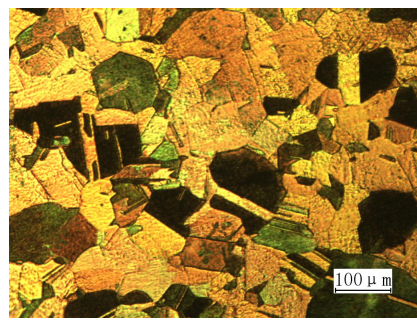

(e) $\mathrm{T}=700^{\circ} \mathrm{C}$

Figure 4. Thermal deformation organization of copper bus bar $\left(\mathrm{e}=50 \%, \quad \dot{\varepsilon}=10.0 \mathrm{~s}^{-1}\right)$ 
Table 1. The average grain size $(\mathrm{d} / \mu \mathrm{m})$ of copper bus bar under various thermal deformation conditions $(\mathrm{e}=50 \%)$

\begin{tabular}{|c|c|c|c|}
\hline Strain rate $/ \mathbf{s}^{-1}$ & $\mathbf{5 0 0}^{\circ} \mathbf{C}$ & $\mathbf{6 0 0}^{\circ} \mathbf{C}$ & $\mathbf{7 0 0}^{\circ} \mathbf{C}$ \\
\hline 0.01 & 53.5 & 52.84 & 78.48 \\
\hline 0.1 & 52.5 & 40.94 & 57.08 \\
\hline 1.0 & 53.3 & 43.04 & 44.72 \\
\hline 10.0 & 51.8 & 57.48 & 63.8 \\
\hline
\end{tabular}

Table 1 lists the average grain size of copper bus bar under various thermal deformation conditions. Grain morphologies in Figure 1 to 4 and data in Table 1 indicate that

(1) When the deformation amount is $50 \%$, at the same deformation temperature, with the increase of strain rate, the microstructure of copper bus bar is improved obviously and the dynamic recrystallization occurs to generate no distortion grain. And the dynamic recrystallization grain grows bigger while the strain rate increases.

(2) When the deformation amount is $50 \%$, at the same strain rate, with the increase of deformation temperature and deformation degree, the copper bus bar undergoes partial dynamic recrystallization and complete dynamic recrystallization, and the local growth and complete growth after dynamic recrystallization. The grain size increases gradually as the temperature increases.

To be concluded, the dynamic softening behavior of copper bus bar at high temperature is affected greatly by both the deformation temperature and the strain rate. The influence of deformation temperature is small when the strain rate is low. And it's obvious when the strain rate is high. That means the copper bus bar is a thermal sensitive and strain rate sensitive material ${ }^{[4 \cdot 5]}$. The higher the strain rate and the deformation temperature are, the sooner the dynamic recrystallization happens, the more completely the microstructure recrystallization is.

\subsection{Effects of thermal deformation conditions on the microstructure of the copper bus bar}

\subsubsection{Effects of the strain rate on the microstructure of the copper bus bar}

Figure 1 to 4 shows that the temperature of recrystallization nucleation decreases with the increase of the strain rate when the deformation temperature is settled. With a strain rate of $0.1 \mathrm{~s}^{-1}$, recrystallization nucleus appeared at $500^{\circ} \mathrm{C}$. When the strain rate is $1.0 \mathrm{~s}^{-1}$, a small amount of recrystallization nucleus formed between $400^{\circ} \mathrm{C}$ to $500^{\circ} \mathrm{C}$. When the strain rate increases to $1.0 \mathrm{~s}^{-1}$, the recrystallization nucleation happens at $400^{\circ} \mathrm{C}$. When the strain rate reaches to $10.0 \mathrm{~s}^{-1}$, major nucleus has appeared at $400^{\circ} \mathrm{C}$.

Table 1 show that the average grain size of the copper bus bar decreases at the beginning and then increases when the strain rate varies within $0.01 \mathrm{~s}^{-1}$ to $1.0 \mathrm{~s}^{-1}$. At a low strain rate, the dynamic recrystallization happens at $500^{\circ} \mathrm{C}$. The average grain size is relative small when the temperature reaches $600^{\circ} \mathrm{C}$ and becomes bigger at $700^{\circ} \mathrm{C}$.
At high strain rate $\left(10.0 \mathrm{~s}^{-1}\right)$, the recrystallization nucleation happens earlier. The formation of recrystallization grain almost completes at $500^{\circ} \mathrm{C}$. Though the temperature continues climbing, only the grain size grows.

\subsubsection{Effects of the deformation temperature on the microstructure of the copper bus bar}

Figure 1 to 4 also shows that at the same strain rate, the as-cast microstructure of the raw material gradually deforms into the recrystallized grains with the increase of deformation temperature and the deformation degree. The grain size grows gradually along with the temperature increases. Figure 2 presents deformations of the microstructure when the strain rate is settled as $0.1 \mathrm{~s}^{-1}$. When the temperature is $200^{\circ} \mathrm{C}$, almost all grains are elongated into strip along the compression direction. At this stage, only physical deformations happen. When the temperature continues rising to $400^{\circ} \mathrm{C}$, the large angle grain boundary become fuzzy and dynamic recrystallizaiton nucleation happen in some parts. The increase of temperature drives recrystallization nucleations, which is almost completed at $600^{\circ} \mathrm{C}$. At this stage, almost all original grains have been replaced by recrystallization nucleus, whose size continues growing along with the increase of temperature ${ }^{[6]}$.

During the thermal deformation process, grains are prone to recrystallizatied dynamically under higher temperature and lower strain rate because of the time grains required to be softened. Lower strain rate provides grains enough time to grow up and then recrystallizated. On the contrary, grains have not enough time for their deformation when the strain rate is high. That is to say, higher temperature provides greater drive for grain growth, which will minimize the grain deformation preparation time. Less time for grain growth makes recrystallization nucleation as soon as possible. Experimental results are consistent with the research about thermal formation behavior of $\mathrm{Gu}-\mathrm{Ni}-\mathrm{Si}-\mathrm{Ag}$ done by Yinhua $\mathrm{Li}^{[7]}$.

\subsubsection{Effects of the deformation amount on the microstructure of the copper bus bar}

Figure 5 shows the metallographic microstructure of the continuous extruded copper bus bar under different deformation amount when the strain rate is $1.0 \mathrm{~s}^{-1}$ and the temperature keeps at $600^{\circ} \mathrm{C}$.

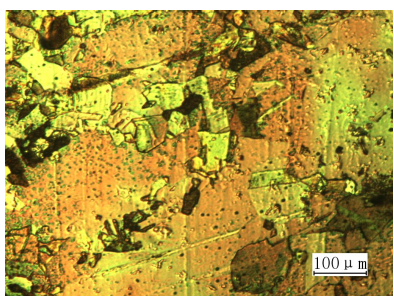

(a) $\mathrm{e}=30 \%$

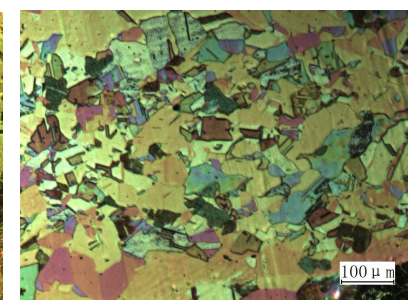

(b) $\mathrm{e}=50 \%$ 


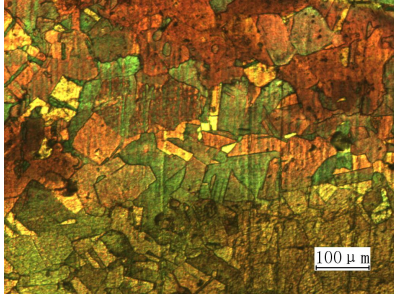

(c) $\mathrm{e}=70 \%$

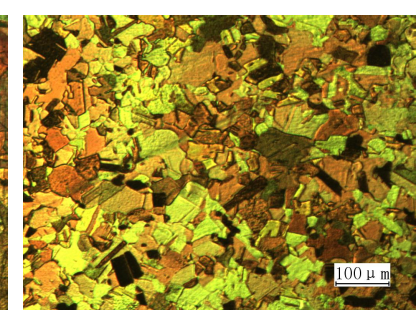

(d) $=90 \%$
Figure 5. The grain microstructure of compressed copper bus bar in different deformation amount $\left(\dot{\varepsilon}=0.1 \mathrm{~s}^{-1}, \mathrm{~T}=600^{\circ} \mathrm{C}\right)$.

Pictures above present the relationship between the recrystallization degree and the deformation amount. When the deformation amount is $30 \%$, there is only a small amount of recrystallization nucleus. When the deformation amount reaches $50 \%$, the number of recrystallization nucleus degree increases greatly. When the deformation is $70 \%$, the recrystallization grains grow obviously. When the deformation amount gets to $90 \%$, the temperature has increased to the high level simultaneously. Under this environment, grains continue growing because of the friction heat between atoms. At this stage, continuous dynamic recrystallization makes grains finer and distribute evenly ${ }^{[8]}$. Therefore, it is more appropriate to keep the deformation degree at $50 \%$.

\subsection{The prediction model of the microstructure of the copper bus bar}

The size of dynamically recrystallizated grains mainly depends on the deformation temperature and the deformation speed. The higher the deformation temperature is, the stronger the grain boundary diffusion and migration is, the bigger the grain size is. Higher deformation speed leaves more dislocation remaining, which results to more defects. Consequently, the recrystallization nucleus increases and grains therefore refined. The final grain size and distribution are determined by the dynamic recrystallization and the arc recrystallization during the thermal process. The main function of the recrystallization grain size model is predicting and controlling the grain size. Accordingly, the parameter $Z$ is used to describe effects of deformation temperature and deformation speed on grain size ${ }^{[9-11]}$, namely:

$$
D=C Z^{-n_{D}}
$$

In the equation, $D$ represents the average grain size, $C$ and $n_{D}$ are the experimental constant, and $Z$ is the zener-holloman parameter. The calculation formula is $Z=\dot{\varepsilon} \exp \left(210.989 \times 10^{3} / R T\right){ }^{[14]}$, and calculation results are shown in Table 2.

Table 2. Parameter $Z$ under various thermal deformation conditions.

\begin{tabular}{|c|c|c|c|c|}
\hline \multirow{2}{*}{$\mathrm{T} /{ }^{\circ} \mathrm{C}$} & \multicolumn{4}{|c|}{$Z / \mathrm{s}^{-1}$} \\
\cline { 2 - 5 } & $0.01 / \mathbf{s}^{-1}$ & $0.1 / \mathbf{s}^{-1}$ & $1 / \mathrm{s}^{-1}$ & $10 / \mathbf{s}^{-1}$ \\
\hline
\end{tabular}

\begin{tabular}{|l|l|l|l|l|}
\hline 300 & $5.4396 \times 10^{34}$ & $5.4396 \times 10^{35}$ & $5.4396 \times 10^{36}$ & $5.4396 \times 10^{37}$ \\
\hline 400 & $3.5618 \times 10^{25}$ & $3.5618 \times 10^{26}$ & $3.5618 \times 10^{27}$ & $3.5618 \times 10^{28}$ \\
\hline 500 & $1.0999 \times 10^{20}$ & $1.0999 \times 10^{21}$ & $1.0999 \times 10^{22}$ & $1.0999 \times 10^{23}$ \\
\hline 600 & $2.3323 \times 10^{16}$ & $2.3323 \times 10^{17}$ & $2.3323 \times 10^{18}$ & $2.3323 \times 10^{19}$ \\
\hline 700 & $5.5439 \times 10^{13}$ & $5.5439 \times 10^{14}$ & $5.5439 \times 10^{15}$ & $5.5439 \times 10^{16}$ \\
\hline
\end{tabular}

Take the natural logarithm on both sides of equation

$$
\ln D=\ln C-n_{D} \ln Z
$$

The regression equation obtained by Table 1, Table 2 and equation 2 is:

$$
\ln D=4.822-0.018 \ln Z
$$

Figure 6 pictures the regression results of $\ln D$ and $\ln Z$, which indicate the correlation coefficient is $0.9447\left(>\mathrm{R}_{0.001}(12-2)=0.8233\right)$. The coefficient indicated that the average grain size value $\ln D$ and $\ln Z$ are in a linear relationship. The result could be an reasonable theoretical basis for the prediction and control of the microstructure of thermal deformed copper bus bar.

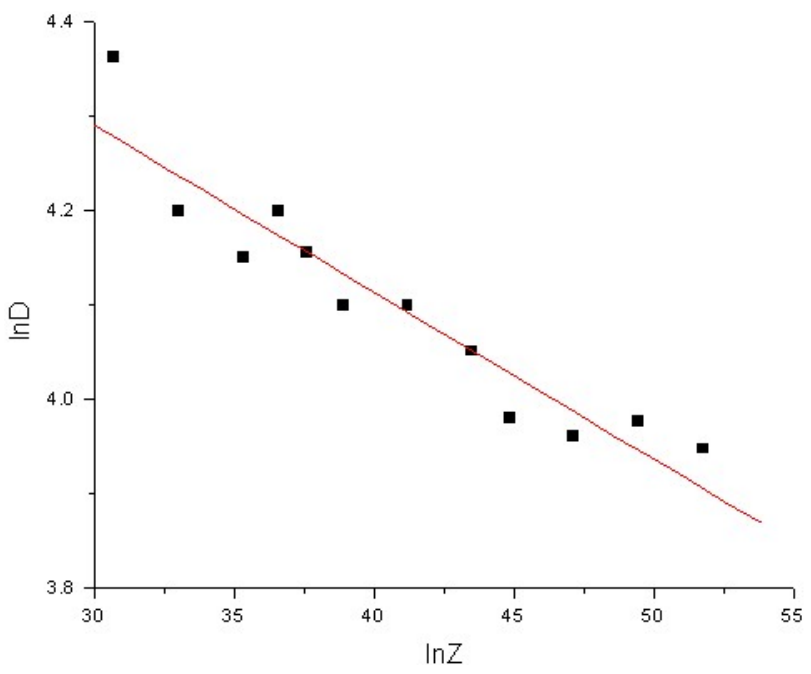

Figure 6. Value $D$ and $Z$ regression results of the grain size of the copper bus bar.

\section{Conclusion}

(1) The dynamic softening behavior of the copper bus bar in thermal deformation is sensitive to the deformation temperature and the strain rate. The copper bus bar is a kink of heat sensitive and strain rate sensitive material.

(2) During thermal deformation, higher temperature combining lower strain rate makes it easier to dynamic recrystallizate. At the same strain rate, the as-cast microstructure of raw materials gradually changes into recrystallized grains along with the increase of the deformation temperature and degree. Then recrystallizated grains grow gradually with the increase of temperature. At the same deformation temperature, the higher the strain rate is, the lower the temperature for 
recrytallization nucleation occurs is. At low strain rate $\left(0.01 \sim 1.0 \mathrm{~s}^{-1}\right)$, the dynamic recrystallization occurs at $500^{\circ} \mathrm{C}$. At high strain rate $\left(10.0 \mathrm{~s}^{-1}\right)$, the recrystallization nucleation moves up, and it is basically completed at $500^{\circ} \mathrm{C}$.

(3) The average grain size value $\ln D$ and $\ln Z$ are in a linear relationship. The result could be a reasonable theoretical basis for the prediction and control of the microstructure of thermal deformed copper bus bar.

\section{References}

1. Hanxiong Huang, Continuous extrusion of self-reinforced high density polyethylene. Polymer Engineering and Science. 1998, 38 (11): 1805-1811

2. Baoyun Song, Zhixin Fan, Jiguang Chen, etc. The characteristics of copper and aluminum continuous extrusion technology and industrial applications. Rare metals. 2004, 28 (1): 257-261.

3. Baoyun Song, Zhixin Fan. Development and Application of Continuous Extrusion Technology in China. Collection of China Non-ferrous Continuous Extrusion Equipment and Technology Applications. June 2007: 7-18.

4. Honggang Zhang, Hui Zhang, Dashi Peng, Qiquan Lin, Liping Meng. KFC copper alloy thermal compression deformation rheological stress. Heat processing process. 2004 (01): 21-24.

5. Miaoquan Li, Shenghui Chen, Xiaoli Li. Microstructure model of titanium alloy at high temperature deformation. Rare metal materials and engineering. 2006, 35 (2): 8-11.

6. Xueyun Kong, Baofeng Wang, Zili Jin, etc. Study on the Evolution of Tissue and Weaving in Crystallization Annealing of Cold Rolling Sheet. Material pyrolysis report. 2007, 28 (4): 98-99.

7. Yinhua Li, Ping Liu, Shuguo Jia, etc. Study on thermal deformation behavior of $\mathrm{Cu}-\mathrm{Ni}-\mathrm{Si}-\mathrm{A}$ alloy. Casting techniques. 2008, 29 (6): 793-798.

8. Bailin Fan, Ganghan Huang. Study on thermoplastic deformation of purple copper. Plastics Engineering Report. 2000,7 (3): 37-39.

9. Ronaldo A N M Barbosa, Henrique C Braga. Analysis of the Occurrence of Dynamic Recrystallization in Hot Rolling by Modeling of the Stess-Strain Curve. ISIJ International. 1992, 32 (2): 257.

10. Devadas $\mathrm{C}$ etal. The Thermal and Metallurgical State of Steel Strip during Hot Rolling: Part 3. Microstructural Evolution. Metallurgical Transactions A. 1991, 22A (2): 335.

11. Sellars C M, Whiteman J A. Recrystallization and Grain Growth in Hot Rolling. Metal Science. 1979, 13 (324): 187-194.

12. Baoyun Song. Theoretical research and engineering practice of continuous extrusion and continuous coating techniques. China Mechanical Engineering. 1998, 9 (8): 69-72.

13. Candong Chu, fubao Di, Yinghong Peng, Xueyi Yan. Effect of extrusion wheel speed during continuous extrusion forming. Mechanical science and technology. 2001 (04): 556-560.

14. Jing Lu, Gaosheng Fu, Xiaoli Lin. Study on the high temperature rheological stress behavior of continuous extrusion copper busbar. Thermal processing. 2012, 41 (20): 11-15. 